\title{
The Safety of Science Activities in an Inclusive Elementary Classroom
}

\author{
Retha Meier*, Nikki L. Murdick, Cara Lytle \\ Saint Louis University, St. Louis, Missouri, USA \\ Email: "rmeier2@slu.edu
}

Received 7 July 2014; revised 25 August 2014; accepted 9 September 2014

Copyright (C) 2014 by authors and Scientific Research Publishing Inc.

This work is licensed under the Creative Commons Attribution International License (CC BY). http://creativecommons.org/licenses/by/4.0/

(c) (i) 0pen Access

\begin{abstract}
As elementary teachers engage their students in scientific inquiry, they often turn to the internet as a resource for rapidly locating scientific activities to use in an inclusive classroom. In these circumstances, however, how can the elementary level teacher know whether the science activities are safe? Even if safety is included within the activities, how does the elementary level teacher know if all safety issues have adequately been addressed? The purpose of this article is to highlight potential safety concerns involving elementary science activities and to provide a checklist to use when evaluating the safety of science activities prior to implementing these activities within the inclusive classroom. If the use of the checklist calls attention to a safety concern in a particular activity, we suggest trying to modify the activity first to make it safe. If the activity cannot be modified to eliminate all safety concerns, then it is recommended that the elementary level teacher search for a different activity that does not pose any hazards. The checklist and supporting background information provided within this paper is intended to help teachers confidently provide a positive learning environment in which all students can safely learn science through inquiry and exploration.
\end{abstract}

\section{Keywords}

Checklist, Elementary, Inquiry, Safety, Science

\section{Introduction}

As children ask questions about their world, elementary teachers must guide them safely through the process of scientific inquiry. Safety for elementary students must be a primary concern when teaching science in order to prevent injuries and the spread of diseases. The National Research Council (NRC) published the National Science Education Standards (NSES) in 1996 that served as goals of achievement within the science education

*Corresponding author. 
community. The National Science Teachers Association (NSTA) has written its own goals based upon professional literature reviews as well as the visionary framework and goals established by NSES. In addition to emphasizing an overarching goal of scientific literacy for all citizens, NSTA Standards provide general guidelines for addressing safety and welfare in effective learning environments, which include students with exceptional needs (see Appendix A).

To assist selecting topic specific lessons that meet NSTA standards, many elementary level teachers turn to the Internet as a resource to quickly find science activities that will stimulate students' curiosity and/or to introduce an inquiry project. But the major question is: are elementary level teachers in inclusive classrooms prepared to address issues of safety that may be inherent in these lessons? When considering the use of the Internet to obtain science activities, several questions arise: 1) Are safety precautions included within the lesson plan? 2) If they are included, are the safety precautions correct? 3) How can elementary teachers determine if a science lesson plan is safe to use with their students? To help answer these questions, the authors retrieved and examined lesson plans for elementary science from the Internet to determine if they would be safe to use in an inclusive elementary classroom. Lesson plans from different science areas (life science, physical science, and Earth science) were investigated.

\section{Safety Evaluation Checklist for Teachers}

In response to the observed absence of safety precautions in many published science lessons and the need for adherence to the NSTA guidelines, a lesson safety checklist was developed to assist elementary teachers in evaluating the safety issues within a science lesson plan. The checklist is divided into the following categories: General Laboratory Safety, Biological Safety (life science), Chemical Safety (physical science), and Rocks and Minerals Safety (Earth science).The checklist provides a quick reference for general safety concerns in addition to guidelines for each of the specific categories. As teachers retrieve lesson plans from the Internet, they are encouraged to use the Safety Evaluation Checklist to determine if the activity is safe to use in their inclusive elementary classroom. By following the safety evaluation procedures outlined in this article, teachers in an inclusive classroom can establish an environment in which all elementary students can safely engage in the scientific inquiry process.

Safety Evaluation Checklist for Teachers

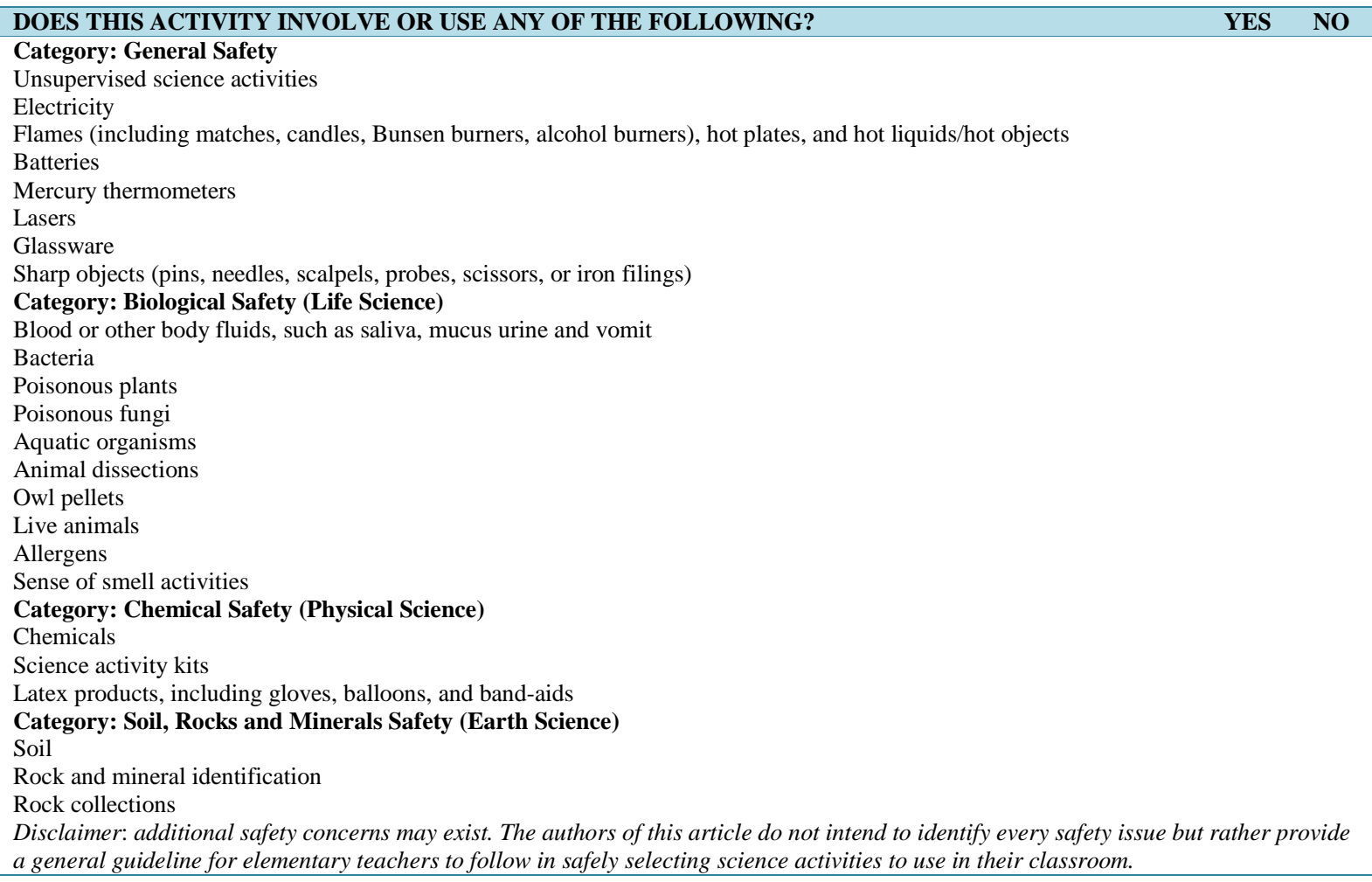




\section{General Laboratory Safety}

Although many elementary schools lack designated laboratory space to complete science activities, general laboratory safety guidelines still need to be established and followed while students are actively involved in science projects. Accidents occur in laboratory situations that may result in physical injuries to students. In this section, we offer suggestions that hopefully will help prevent such accidents and make the laboratory space a safer area for student discovery of scientific principles. General laboratory safety, in this article, addresses concerns regarding supervision of science activities, the safe use of electricity, flames, hot liquids (including hot water); and the appropriate choice and use of science supplies-including batteries, mercury thermometers, lasers, glassware, and sharp objects. It is imperative that all elementary teachers provide a safe learning environment for their students and recognize that they are responsible for the safety and well being of all their students (see Appendix A).

\section{Supervision of Science Activities}

When students are involved in science activities, adult supervision is imperative. Teachers are responsible for teaching their students specific behaviors to ensure safety during a science activity, but teachers also must be aware that students require constant supervision throughout those activities. In addition, teachers need to assure that students understand that all inquiry projects must be reviewed and approved by their teacher prior to doing the investigation. Many science teachers prepare a safety contract that is signed by students and their guardians to clarify these conditions. Students are never permitted to take chemicals, science supplies, and/or equipment home to perform unsupervised science investigations. When unauthorized experiments are performed, or students engage in unsupervised home experiments, the teacher who is in the role of supervisor faces negligence liability.

Safety guidelines are always to be followed regarding handling, labeling, storage, and disposal of chemicals. Chemicals and equipment are to be labeled with needed information, such as content and potential hazards. For children who cannot read or who are just learning to read, pictures can be used in addition to the name. Chemicals are to be stored in a cool, dry, secure area below or at eye level on wooden shelves equipped with a front lip. This ensures that chemicals are secure and that if an earthquake occurs, the likelihood of chemical containers falling from shelves is greatly reduced. For additional information on chemical safety, types of protective apparel to wear, storage, and proper disposal of chemicals, please refer to the Material Safety Data Sheets (MSDS) provided by the chemical supplier on each individual chemical. Material Safety Data Sheets contain information about the safe storage and use of chemicals and can be obtained on-line from Flinn Scientific Supply Company or other chemical suppliers. Material Safety Data Sheets are to be obtained for each chemical used in each science activity, organized alphabetically in a binder, and kept in the science area. This collection of chemical information sheets must be readily available to students, teachers, parents, and administrators at all times.

\section{Electricity}

Students are not to be allowed to use any electrical item in the science area without adult supervision. Extreme caution must be taken when younger elementary students are using electrical equipment. The teacher, as the supervising adult, is responsible for inserting and removing the plug of the electrical device. The proper way to unplug an electrical device is to grasp the plug and gently pull the plug from the outlet, avoiding contact with the metal prongs. An electrical device is never to be removed from the outlet by pulling on the cord.

Specific cautions need to be addressed when using electricity in a designated science area. For example, teachers never place any electrical equipment near a water source in order to avoid electrocution. Anyone handling the electrical equipment must also make sure that his/her hands are dry. Ground Fault Circuit Interrupters (GFCIs) are recommended in outlets that are near water sources and are actually required by law in some states. GFCIs are protective devices placed in outlets that interrupt the circuit in the event that an electrical imbalance is detected. Another electrical safety consideration is whether extension cords can be safely used in a classroom. If extension cords are used, they have to be rated the same level as the circuit breaker for the outlet. If this condition is not met, the extension cord could be overloaded and a fire could result.

\section{Flames and Hot Objects/Liquids}

Science lesson plans retrieved from the Internet at the elementary level addressing the concepts of heat, transfer 
of heat, and temperature will often include the use of boiling or very hot water. As a result, there is a chance that serious burns can result from accidents using hot liquids, an open fire, or hot plates. For this reason, the use of flames, including matches, candles, Bunsen burners, and alcohol burners is strictly forbidden in the inclusive elementary science area. Hot plates used to heat liquids are also not allowed. Hot liquids, including hot water and hot objects are not safe for children to use because of the possibility of causing harm.

\section{Batteries}

Batteries are power sources in which stored chemical energy is converted into electrical energy. Battery types commonly found in a science area include button cell, "AAA", "AA", "C" and "D". According to Roy ([1], p. 91), "batteries (1.5 volts) are safe unless they are short-circuited, become overheated, and explode, which can cause serious burns to the body. Never short-circuit a battery.” Additional safety concerns include the possibility of ingestion and corrosion. In the event that a small button cell battery is ever ingested, emergency medical attention is sought immediately. These small batteries can become lodged and block the digestive and/or respiratory tracts as well as result in internal chemical burns. Batteries will often corrode if left in a battery-powered device (e.g., cameras, flashlights, radios) for an extended period of time. When not in use, all batteries are removed from battery-powered devices. All loose batteries can be stored in a cool, locked area and secured to eliminate contact with metal. In addition, storing batteries in a locked area will minimize chances of ingestion. It is recommended that rechargeable batteries be used in the classroom and that all batteries be recycled when no longer in use.

Elementary teachers often use type " $\mathrm{D}$ " or "C" batteries when their students build electrical circuits. Adult supervision during this activity is essential. Students have been known to place their tongues on batteries out of dares and/or curiosity. Students are to be cautioned to avoid placing their tongue anywhere on the battery. In addition, it is important to caution students doing this activity to use insulated wiring and to keep the circuits closed only for short periods of time.

\section{Mercury Thermometers}

Mercury is a heavy metal with a silver appearance that is used in mercury thermometers. This toxic metal can enter the body through inhalation, ingestion, and direct contact. In young children, the ingestion of mercury can result in severe neurological consequences. If a mercury laboratory thermometer breaks, harmful vapors can be released into the atmosphere. Therefore, the use of mercury thermometers is prohibited in the elementary setting. For these reasons, alcohol thermometers or electronic temperature detection measurement systems (infra-red, thermocouples) are used in place of mercury thermometers. Finally, to reduce the risk of alcohol thermometer breakage, the use of thermometers that are secured to a metal or plastic backing is recommended. This design prevents thermometers from rolling off of a bench top and shattering upon impact.

\section{Lasers}

The word "laser" is an acronym for the words: light, amplification, by stimulated emission of radiation. Because children "play" with lasers when they play Laser Tag, they might believe that all lasers are safe. However, this is just not true. Lasers are classified into four categories according to maximum power output, wavelength, and their ability to cause damage to exposed individuals. For example, Class I lasers are believed to be safe and cause no physical harm to individuals exposed to this type of laser whereas Class IV lasers are known to present severe hazards to both eyes and skin. Lasers are used in science activities to investigate holograms, reflection, refraction, diffraction and interference of light. Teachers also often use laser pointers to direct student attention to pertinent lesson material. According to Roy ([1], pp. 92-93), the following recommendations are made:

Never point a laser pointer of any power at anybody. Pointers should be used to point out or emphasize inanimate objects such as slide images or laboratory apparatus.

Laser pointers are not toys and should not be used by young students. It is recommended that the batteries be taken out of the pointer when it is not in use.

Laser pointers above $5 \mathrm{~mW}$ should never be used.

Throughout the United States, lasers have been used to shine into aircraft during night flights. This is an extremely dangerous situation and it's illegal. Students are never to point lasers at aircraft. 


\section{Glassware}

Glassware is easily broken and this rapidly translates into physical injury to the child as well as a potential biohazard. It is highly recommended that all glassware be replaced with plastic containers, and it is very important to inform students that labware is designated for scientific purposes only and to avoid using the containers for eating and/or drinking. Finally, it is forbidden to have students attempt to insert thermometers or glass tubing into rubber stoppers because of the high probability of breakage resulting in physical harm.

\section{Sharp Objects}

Science lessons often include the use of sharp objects that could result in physical injury such as pins, needles, scalpels, probes, or scissors with sharp points. For example, lessons for making a pinwheel suggest pushing a straight pin into a wooden dowel. How many students will end up with the pin stuck through their finger? Students can and do injure themselves or others with sharp objects. As with broken glass, a potential biohazard can result. Therefore, sharp objects are not to be used in the elementary science area. Substitutions include blunt, non-pointed objects.

\section{Biological Safety (Life Science)}

The section on biological safety addresses blood and other body fluids, such as saliva, mucus, urine, and vomit; any living or preserved organism, including sections of organisms; as well as anything that came out of that organism, such as owl pellets. Also included in this section, are allergens and activities involving human physiological senses.

\section{Blood and Other Body Fluids}

Blood-borne pathogens are responsible for a number of diseases, including acquired immune deficiency syndrome (AIDS) and hepatitis [2]. Saliva is another potential biohazard that could pose a health risk to students. One lesson plan retrieved from the Internet instructed students to bite into a piece of Styrofoam to make dental impressions and match these teeth impressions with bite marks left on a piece of cheese in order to determine who ate the cheese. This activity is not safe for a number of reasons. First, saliva poses a potential biohazard. This lesson plan also presents choking hazards as the student bites into a piece of Styrofoam. Sanitation problems exist with preparing the cheese. In addition, it is also advised that teachers avoid using Styrofoam because it is not an environmentally friendly substance. Therefore, activities that involve blood or other body fluids, such as saliva, mucus, urine, and vomit are not safe for use in school classrooms and are not be used.

\section{Bacteria}

Bacteria are prokaryotic, microscopic organisms. Students are often curious about which mouthwash will "kill" bacteria or which antimicrobial soap and/or hand sanitizer is most effective. Lesson plans are available online that outline how to grow bacteria in Petri dishes. With the mouthwash inquiry, a student is instructed to swab his/her mouth and inoculate a sterile saline solution with this swab. One-milliliter samples are removed from the saline solution and added to test tubes containing various brands of mouthwash. A clean swab is used to transfer a sample from the mouthwash-saline mixture and smear onto a labeled Petri dish containing nutrient agar. Cultured bacteria become concentrated colonies of bacteria. If these colonies are contacted, and if the bacteria are pathogenic, the child could become seriously ill. For this reason, it is not advisable to culture bacteria in the elementary classroom. In addition, special precautions must be taken in the disposal of bacterial cultures. Bacterial cultures cannot be thrown into the general trash. One lesson retrieved from the Internet provided clean up directions that recommended the simple disposal of bags containing bacterial growth in school trash cans. This practice is not supported by current safety guidelines. The NSTA Ready-Reference Guide to Safer Science makes the following recommendation:

Some schools use Petri plates and grow bacteria or mold. These types of activities are not advocated, but, if you do use them, disposal necessitates sterilization in a pressure cooker, microwave, or autoclave. Also, appropriate labeling and packaging are required ([1], p. 57).

Not only must bacterial and fungal cultures be destroyed prior to disposal, appropriate labeling and packaging 
are also required.

\section{Poisonous Plants}

Many classrooms include a variety of plants, many of which may be poisonous and may pose health hazards to children who touch or ingest them [3]. A number of plants used in floral arrangements are toxic, including arrowhead plant, caladium, croton, and philodendron. During December, teachers often bring mistletoe, poinsettia, and holly plants into the classroom for decorations. All of these plants are toxic if ingested and are not to be brought into the inclusive elementary classroom. If a lesson requires using plants, the teacher must make sure that the plants are nontoxic.

Seeds are often used in the elementary classroom in germination studies. Seeds that have been coated with chemicals are not to be used in classroom activities because the chemicals are poisonous and could cause serious harm if the children ingest the coated seeds or the chemical comes in contact with their skin.

Teachers planning field trips and hikes into nature must consider plants that could cause harm such as stinging nettle, poison ivy, poison oak, and jack-in-the-pulpit. Students are to be reminded not to pick or eat any plants or plant parts while on nature hikes.

\section{Poisonous Fungi}

Mushrooms belonging to the genus Amanita look very similar to store-bought mushrooms but are deadly poisonous. Children are encouraged to make observations of fungi but are never to touch them in nature. An activity retrieved from the Internet instructs children to go into nature and collect mushrooms to make spore prints. Mushroom caps are removed from the stipe and placed on a sheet of paper, gill side down. As spores are released from the gills, a spore print is produced on the paper. If mushrooms are to be used in such activities, teachers are to avoid using mushrooms found in nature. Instead fresh mushrooms purchased from a grocery store can be used.

\section{Aquatic Organisms}

Children frequently engage in inquiry projects by testing the water quality and/or searching for macro- and micro-aquatic organisms in bodies of water in their community. It is recommended that children wear non-latex gloves while collecting these water samples. Children are to always wash their hands thoroughly after working with water samples from nature since the water could be contaminated with harmful chemicals and/or pathogens. This suggestion is supported in the Missouri Elementary Science Safety Manual ([4], p. 14). Finally, the bench area, microscopes, and tools are to be thoroughly disinfected at the end of each activity.

\section{Animal Dissections}

Animal dissections are not recommended for use with elementary students ([4], p. 19). Animal dissections are the cutting of preserved animals in order for students to learn about the organs, tissues, etc. of various animals. Dissection usually requires the use of tweezers, scalpels, and/or scissors. Injury from these sharp and other pointed tools can result in bodily injury. In addition, chemicals used in preserving the animals are toxic and exposing children to these toxins is to be avoided. For these reasons, it is suggested that virtual dissections and/or models be used instead.

\section{Owl Pellets}

An owl's diet consists of moles, voles, mice, rats, birds, and a variety of other small prey. Owl pellets are comprised of indigestible parts (bones, fur, and beaks) that are compacted to form a pellet and later regurgitated by an owl. If owl pellets are to be dissected, always purchase them from a reliable source, such as Carolina Biological Supply Company. Prior to shipping, owl pellets are fumigated to eliminate harmful pathogens. Before using owl pellets, the teacher must make sure none of the students or teaching staff have allergies to feathers or fur, since this, along with small bones, are often contained within owl pellets. It is not advisable to collect owl pellets from nature and use them in the classroom because of the possibility of transmission of rodent-carrying diseases. Children dissecting owl pellets must wear appropriate safety apparel including lab coat/apron, non-latex 
gloves, and a facemask. Children are to wash their hands after removing their safety apparel. Because of the risks involved with the use of owl pellets, teachers may want to identify a safer activity such as having students engage in a virtual owl pellet dissection.

\section{Live Animals}

If live animals are a part of the classroom, they must be treated in a safe, humane, and ethical manner. Healthy animals are to be purchased from reliable dealers. In addition, students are not allowed tobring their pets to school because of stress caused to the animal as well as the potential for the animal to harm students. Teachers must be aware of and respect legal restrictions on collecting animals for educational purposes. All teachers are encouraged to check with the state department of conservation codes for policies on collecting wild animals and bird nests for use in the classroom. For example, in the United States it is illegal to collect bird nests, feathers, or eggs of any protected bird without federal and state permits. In addition, wild animals, such as reptiles and amphibians, pose the risk of transmitting Salmonella to students who touch the animals or the water in which they live. Poisonous and/or constricting animals must never be allowed in the classroom either to keep or to show.

\section{Allergens}

Allergic reactions to various nuts and other items, is an increasing concern in today's classrooms. Today, many students are allergic to peanuts. In the past, an engaging science activity used to enhance students' observation skills was to have the students carefully examine an entire peanut (with shell). Once the peanut has been observed, measured, drawn, and weighed, it is placed in a pile with other peanuts, mixed together, and then the students are asked to find their specific peanut. This activity, today, is considered unsafe because of the risk that peanuts pose in eliciting severe allergic reactions. An alternative activity would be to replace the real peanuts with a photocopy of the peanuts. A replacement activity could also be to use a collection of leaves from one species of nontoxic tree. In addition to peanuts, teachers must be aware of other allergens such as mold, pollen, and pet dander. Special considerations are to be taken to ensure that all activities that might contain allergens have been identified, replaced, or omitted.

\section{Sense of Smell Activities}

The senses are often a topic of investigation in the elementary science classroom and a favorite is the sense of smell (olfactory sense). Teachers must use caution with activities that include the sense of smell. A lesson activity focusing on the sense of smell was retrieved from the Internet in which substances such as garlic powder, onion powder, cocoa, mixed spices, and rubbing alcohol were placed on cotton balls in individual baby food jars. This activity is considered unsafe for use in an elementary classroom because of the potential of inhaling powders (garlic or onion powder, cocoa, and mixed spices). In addition, inhaling rubbing alcohol can have toxic effects and therefore must be avoided. For this reason teachers always avoid using powders in activities where students may inhale them. It is recommended that teachers substitute safe liquids such as vanilla extract, mint extract, or other safe extracts. In addition, inedible liquids that could be harmful if swallowed, such as liquid laundry detergent or shampoo, are not considered to be acceptable substitutions.

\section{Chemical Safety (Physical Science)}

The area of chemical safety deals with chemicals that children might use in their physical science activities, investigations, and/or inquiry projects. It is imperative that elementary teachers become knowledgeable about chemicals that may be used in science activities in the elementary classroom.

\section{Chemicals}

Chemicals commonly used for culinary purposes are considered safe to use in the elementary classroom. These include such chemicals as white vinegar ( $5 \%$ glacial acetic acid, $\mathrm{CH}_{3} \mathrm{COOH}$ ), pure vanilla extract (vanillin, $\mathrm{C}_{8} \mathrm{H}_{8} \mathrm{O}_{3}$ plus several hundred other different compounds), baking soda (sodium bicarbonate, $\mathrm{NaHCO}_{3}$ ), baking powder[a combination of baking soda, $\mathrm{NaHCO}_{3}$ plus crème of tarter, $\mathrm{KHC}_{4} \mathrm{H}_{4} \mathrm{O}_{6}$ and starch, $\left(\mathrm{C}_{6} \mathrm{H}_{10} \mathrm{O}_{5}\right)_{n}$ ], sugar (sucrose, $\left.\mathrm{C}_{12} \mathrm{H}_{22} \mathrm{O}_{11}\right)$, corn starch $\left[\left(\mathrm{C}_{6} \mathrm{H}_{10} \mathrm{O}_{5}\right)_{n}\right]$, table salt $(\mathrm{NaCl})$, and vitamin $\mathrm{C}\left(\mathrm{C}_{6} \mathrm{H}_{8} \mathrm{O}_{6}\right)$, water $\left(\mathrm{H}_{2} \mathrm{O}\right)$, club 
soda, and olive oil. It is essential when using chemicals that young children are given specific instructions. The teacher is to emphasize that the children are using these "chemicals" in an entirely different way and they must not consume them during their use in the science laboratory. One activity in which many teachers use chemicals is mimicry of volcanic eruptions. It is recommended that teachers avoid mixing baking soda with vinegar in this activity because of the violent reaction that can occur. Bleach and ammonia are not used in the elementary classroom because they are too dangerous. When these two compounds are mixed, deadly chlorine gas can be released.

Mixing chemicals as noted previously is a serious problem when completing science activities with young children. It is essential that children understand that they are never to mix chemicals just for fun to see what happens, unless instructed to do so by their science teacher. One safe chemical mixing activity retrieved from the Internet is making slime from corn starch $\left[\left(\mathrm{C}_{6} \mathrm{H}_{10} \mathrm{O}_{5}\right)_{n}\right]$ and water $\left(\mathrm{H}_{2} \mathrm{O}\right)$. It encourages free exploration in which students can use different amounts of cornstarch and water to determine the effects of varying concentrations of each ingredient. One box of cornstarch is mixed with $237 \mathrm{ml}$ of water to make a nontoxic polymer. Children can safely explore this chemical process by adding more or less water and comparing the results.

Using chemicals to grow crystals is another often used activity. An activity of this type was retrieved from the Internet and was listed as being appropriate for Grades 1 through 12. In this activity silver nitrate was used to grow crystals on copper wire. This is a dangerous activity for young children as skin burns can result from exposure to silver nitrate, Additional symptoms include blisters, loss of vision, shock, collapse, and blue coloration to lips, skin or fingernails. Because of these hazards posed by silver nitrate, this activity is considered unsafe for use in an elementary classroom.

\section{Science Activity Kits}

Science activity kits (curricular kits) are sets of lessons or activities that include directions and materials for implementing various science activities. Teachers are encouraged to use caution when purchasing kits from a supply company as they may contain poisonous or other inappropriate chemicals. Our suggestion is to contact the company that sells the kit and request Material Safety Data Sheets on every chemical contained within the kit. This will allow the teacher to determine if the kit is both safe and age appropriate.

\section{Latex Products}

The use of products containing latex, such as gloves, balloons, and Band-Aids are to be avoided whenever possible [2]. Young children may have latex allergies and not even be aware of this condition. If a child is allergic to latex, initial symptoms might include itching, rash development, sneezing, runny nose, watery eyes, scratchy throat, and coughing. Allergic reactions to latex can result in a life-threatening situation with severe symptoms including difficulty breathing, confusion, wheezing, and loss of consciousness. In the event of a severe allergic reaction, immediate medical attention is necessary.

\section{Soil, Rocks and Minerals Safety (Earth Science)}

Earth science includes the study of varying aspects of the earth itself, including geology, geophysics, soil science, glaciology, oceanography and atmospheric sciences. In the inclusive elementary classroom, students often enjoy studying soil samples as well as collecting rocks and minerals. It is not uncommon to see rock collections in elementary classrooms. An abundance of Earth science activities can be found on the Internet - including those that encourage students to inquire about organisms living in a soil environment as well as soil composition and erosion.

\section{Soil}

Soil is a natural substance made of organic and mineral components. Teachers are encouraged to use caution when working with soil. If the activity is occurring outside, hidden dangers, such as broken glass, rusty nails, wire, and even syringes can be buried within the soil. Soil samples from the outdoors also contain mold that can elicit allergic reactions in individuals with specific allergies. Another factor to consider is the potential for soil samples to contain heavy metals, which are endemic in many areas of the country, such as the "lead belt" in southern Missouri. For these reasons, it is recommended that elementary teachers use sterilized potting soil for 
inquiry activities requiring the use of soil.

\section{Rocks and Minerals}

Rock collections are common in elementary classrooms. These collections frequently are the result of collections made by enthusiastic students, donations, personal collections, and purchases from rock dealers, or educational companies, or science centers. The rocks and/or minerals may be glued to a piece of cardboard with the name of the rock/mineral printed beneath the stone. An additional method of identifying the specimen is to imprint a number on a small circle that is glued to the rock with a corresponding key that accompanies the collection. After many years of use, the rocks and the corresponding identification tags may become dislodged from the cardboard. If you are fortunate enough to inherit such a collection and if you are new to the rock world, you are probably left wondering "What are these rocks and are they safe?" Identification of these rocks can be a problem as rocks in collections that were not for student handling or use in tactile activities may contain harmful substances (e.g. lead, arsenic, and mercury). Many rock collections include galena that contains lead sulphide, and cinnabar that contains mercury sulphide. Another item that may be found in these collections is asbestos, a mineral that causes asbestosis. Other rocks included in collections are arsenopyrite, realgar, and orpiment that all contain arsenic, a highly toxic substance. For these reasons, it is suggested that you keep only specimens that are identified as safe rocks and minerals—-those that do not contain lead, arsenic, asbestos, mercury, and other harmful substances.

\section{Sand}

Sand, also known as silica $\left(\mathrm{SO}_{2}\right)$, is often used in the classroom for erosion and plant growth activities. Sand can easily be obtained from sandy riverbanks. This sand, however, is hazardous because it may contain fine particles of silica, also known as microcrystalline silica. Inhaling fine silica dust $\left(0.1 \mathrm{mg} / \mathrm{m}^{3}\right.$ allowed by OSHA) over time can result in bronchitis, silicosis, and even cancer. Since sand removed from riverbanks may contain microcrystalline silica, it is recommended to purchase and use safe sandbox sand.

\section{Legal Background}

Teachers who plan to use science inquiry activities in their classrooms have a duty of care to ensure a safe learning environment. Prosser et al. [5] defines "duty of care" as an obligation recognized by law that requires conformance to a certain standard of conduct that protects others from unreasonable risk. In addition, Prosser et al. [5] identify three main areas of legal responsibilities identified for the elementary teacher including the duty of instruction, supervision, and maintenance. The duty of instruction includes providing students with age appropriate, accurate directions before they engage in any science experience. Procedures used in the science experience are to be explained clearly, and all risks and/or hazards must be identified and addressed. Teachers guide students to understand the difference between appropriate and inappropriate conduct during the science experience so that they can safely engage in the activity. Teacher demonstrations to students of how to obtain help in an emergency are essential. In addition, students are to understand the importance of always reporting accidents to a teacher or other adult in the immediate vicinity.

Duty of supervision means that the teacher has a primary duty to supervise students at all times. The teacher must never leave the classroom during any instruction, leaving students unattended and unsupervised at any time. In fact, very young children and students with special needs may require additional attention and supervision.

Duty of maintenance requires the teacher to provide a safe environment in which students can learn. Students need adequate space to move around freely. The floor is to be clear to eliminate students from tripping over book bags and other such items. In addition, the bench top is to be clear so that adequate workspace is available. Ideally, the room is to contain two possible exits.

Equipment is to be inspected on a regular basis. Defective equipment is never to be used in the classroom. Efforts in resolving safety dilemmas within the classroom are to be documented for future reference with written reports filed with the appropriate supervisor or administrator. These reports include concerns related to the maintenance, repair and disposal of defective equipment or the elimination of potentially hazardous conditions. It is recommended that teachers keep a copy of all these letters as documentation.

All teachers, but especially those in inclusive classrooms who plan to implement science activities, must be 
aware of safety and welfare procedures to ensure the safety of all of their students. This awareness includes knowing local, district, and state statutes regarding safety regulations. Safety regulations and procedures will need to be taught throughout the year, not just at the beginning of the school year, and is to be reviewed frequently. Safety posters as well as safety guidelines are to be displayed and explained to students. Safety guidelines include basic safety information such as prohibiting food and drinks in the laboratory, not allowing students to wear loose-fitting, baggy clothing and/or dangly jewelry, insisting that students secure long hair, and that all lab participants wear appropriate clothing such as close-toed shoes and apparel that covers the upper and lower body. Appropriate safety apparel that must be worn in the science laboratory, that is, during a science activity includes laboratory coats or aprons, non-latex gloves, and American National Standards Institute (ANSI) coded Z87 goggles. When goggles are to be used by the students, they are to be disinfected in an ultraviolet cabinet or disinfected after each use according to an acceptable procedure. Sharing goggles without disinfecting can result in the spread of contagious conditions including head lice, ringworm, and/or conjunctivitis. One suggestion is to have students purchase their own personal goggles, label the goggles with their name, and avoid sharing them. Finally, proper hand washing is required of all students after each science activity [2], and teachers make sure that laboratory tables and benches are cleaned and disinfected after each use.

\section{Conclusions}

Prior to introducing a science activity or investigation to students in an inclusive elementary classroom, teachers must carefully review the activity and ask some important questions about the safety of the lesson. The Safety Evaluation Checklist for Teachers is available for teachers to use to determine if an activity retrieved from the Internet is safe to use in their classroom. Prior to implementing the activity in the classroom, the teacher is to complete the entire activity her/himself. If the teacher believes that the activity is not safe for the age or the ability level of the children in his or her classroom, modifications can be considered. For example, in one activity found on the Internet, lemon juice was used to write a secret message using a toothpick on a piece of paper. The paper was then held over a flame until the message became visible. Students may find this activity interesting. However, based on the Safety Evaluation Checklist for Teachers, this activity is not safe, due to the use of an open flame. This activity can, however, be modified by substituting a hair dryer under adult supervision in the place of open flame. In some cases, though, the activity cannot be changed and is therefore avoided.

Elementary teachers are encouraged to use the process of scientific inquiry to teach science to all their students, but in doing so, they must also be careful to ensure student safety. Essentially, teachers must ensure that all demonstrations, activities, science investigations and inquiry projects are safe as well as age appropriate. The Safety Evaluation Checklist for Teachers is included as a quick reference to assist teachers in recognizing elements of science activities that may make them unsafe for use in an inclusive classroom with elementary age students. A mark in the yes column as a response to a checklist prompt results in the teacher questioning whether a safe substitution can be made. Without a safe substitution, the teacher is to search for another activity that meets all of the safety requirements listed in the checklist and meets the goals of the curriculum activity. Choosing science activities carefully allows all elementary students to explore science in a safe manner.

\section{References}

[1] Roy, K.R. (2007) The NSTA Ready-Reference Guide to Safer Science. NSTA, Arlington.

[2] Edens, R., Murdick, N. and Gartin, B. (2003) Preventing Infection in the Classroom: The Use of Universal Precautions. Teaching Exceptional Children, 35, 62-65.

[3] Edens, R. and Murdick, N. (2008) Are There Toxic Plants in Your Classroom? A Resource for Educators of Children with Exceptional Needs. Teaching Exceptional Children Plus, 4, 2-14.

[4] Lemons, J. (1996) Missouri Elementary Science Safety Manual. Missouri Department of Elementary and Secondary Education, Jefferson City.

[5] Prosser, W.L., Keeton, W.P., Dobbs, D.B., Keeton, R.E. and Owen, D.G. (1984) In: Keeton, W.P., Ed., Prosser and Keeton on Torts, 5th Edition, West Group, St. Paul. 


\section{Appendix A}

NSTA Standard 9 Safety and Welfare

Teachers of science organize safe and effective learning environments that promote the success of students and the welfare of all living things. They require and promote knowledge and respect for safety, and oversee the welfare of all living things used in the classroom or found in the field. To show that they are prepared, teachers of science must demonstrate that they:

a) Understand the legal and ethical responsibilities of science teachers for the welfare of their students, the proper treatment of animals, and the maintenance and disposal of materials.

b) Know and practice safe and proper techniques for the preparation, storage, dispensing, supervision, and disposal of all materials used in science instruction.

c) Know and follow emergency procedures, maintain safety equipment, and ensure safety procedures appropriate for the activities and the abilities of students.

d) Treat all living organisms used in the classroom or found in the field in a safe, humane, and ethical manner and respect legal restrictions on their collection, keeping, and use.

\section{Web Links}

Americans with Disabilities Act of 1990 (ADA). www.usdoj.gov/crt/ada/adahom1.htm and www.ada.gov/pubs/ada.htm

American Chemical Society. www.chemistry.org

Animals in Education, Humane Society of the United States. www.hsus.org/ace/11368

Building Officials and Code Administrators (BOCA). www.iccsafe.org/help/redirect-bocai.html

Centers for Disease Control and Prevention. www.cdc.gov

FLINN Chemical Reference Manual: www.flinnsci.com/

Individuals with Disabilities Education Act (IDEA).

www.ed.gov/offices/OSERS/Policy/IDEA/index.html and

www.4.law.cornell.edu/uscode/20/1400.html

International Code Council (ICC). www.iccsafe.org

Laboratory Chemical Safety Summaries, Howard Hughes Medical Institute.

www.hhmi.org/science/labsafe/lcss/index.html

National Fire Protection Association (NFPA). www.nfpa.org

NSTA Standards for Science Teacher Preparation.

www.nsta.org/pdfs/NSTAstandards2003.pdf

National Safety Council. www.nsc.org/

NSES (National Science Education Standards).

www.nap.edu/readingroom/books/nses

NSTA (National Science Teachers Association).

www.nsta.org/pdfs/NSTA standards 2003.pdf

Missouri Department of Conservation: Missouri Wildlife Code. mdc.mo.gov

Missouri Elementary Science Safety Manual.

dese.mo.gov/divimprove/curriculum/science/manuals/elemman.pdf

MSDS Online. www.msdsonline.com

Occupational Safety \& Health Administration. U.S. Department of Labor. www.osha.gov

Office of Environmental Health and Safety, University of Virginia.

www.keats.admin.virginia.edu/home.html

Office of Research Services, National Institutes of Health. www.ors.od.nih.gov/service

Science Safety, Laboratory Safety Institute. www.labsafety.org

US Environmental Protection Agency (EPA). www.epa.gov 
Scientific Research Publishing (SCIRP) is one of the largest Open Access journal publishers. It is currently publishing more than 200 open access, online, peer-reviewed journals covering a wide range of academic disciplines. SCIRP serves the worldwide academic communities and contributes to the progress and application of science with its publication.

Other selected journals from SCIRP are listed as below. Submit your manuscript to us via either submit@scirp.org or Online Submission Portal.
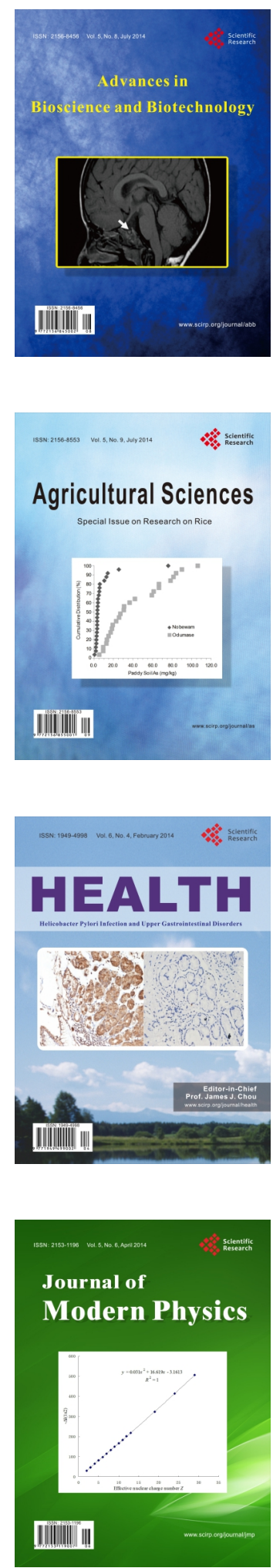
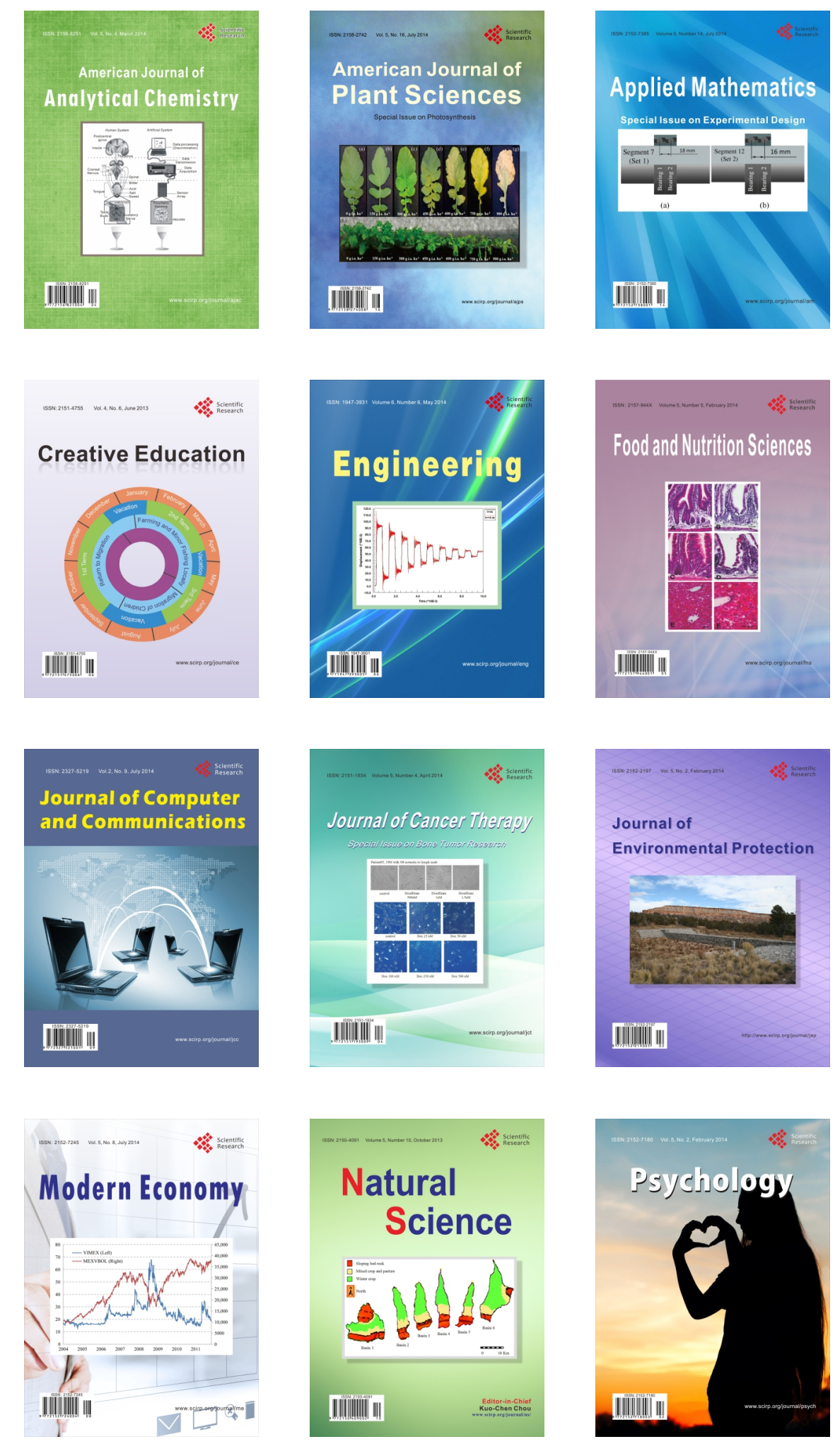